\title{
Critical reflection \\ and dialogical \\ learning design: \\ - moving MOOCs beyond \\ unidirectional transmission of \\ content
}

\section{Kim Haagen Mathiesen}

Social Educator, MA-student

Currently studying MA in ICT-based

Educational Design at CUDIM, Aarhus University. Employed at Treatment Home \& School Eggertshus.

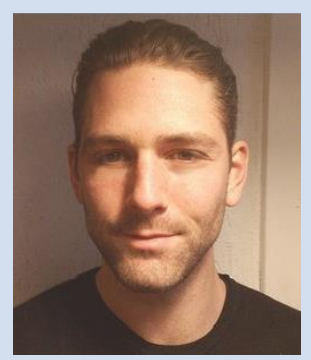

\section{Mathias Helbo}

\section{Nedergaard}

\section{Teacher, MA-student}

Currently studying MA in ICT-based Educational Design at CUDIM, Aarhus University.

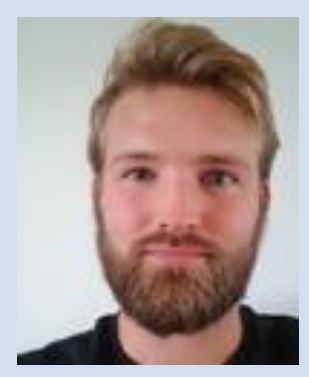




\section{Rikke Toft Nørgård}

Associate professor

Associate professor in educational design \& technology at Center for Teaching Development and Digital Media, Aarhus University.

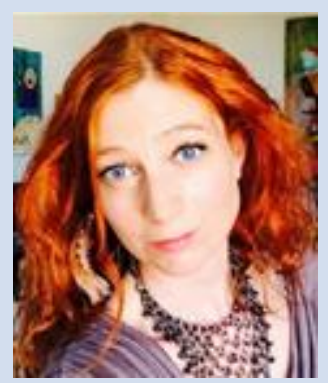


Kim Haagen Mathiesen is working as a Social Educator with children with attachment disorders at Treatment Home and School Eggertshus. Here his work is focused on incorporating ICT in the children's education and establishing informal IT learning labs with the children. Kim is a student at Center for Teaching Development and

Digital Media at Aarhus University, where he is studying ICTbased Educational Design. He is currently working on his master thesis in the subject area of MOOCs.

Mathias Helbo Nedergaard is a former Private School Teacher. Mathias is a student at Center for Teaching Development and ICT-based Educational Design at Aarhus University, where he is currently working on his master thesis.

Rikke Toft Nørgård is associate professor in educational design and technology at the Center for Teaching Development and Digital Media, Aarhus University, Denmark Her work has a focus on innovation in higher education teaching and learning through the use of design thinking, philosophy of education and hybrid learning design. Within this field she is working on developing a value-based visiondriven approach to learning design that uses design thinking as a pathway to support teachers in becoming innovative in their own practice and to create new futures for students in higher education. Rikke Toft Nørgård is also core member of the Center for Higher Education Futures where she, together with Professor Susan Wright, is leading the research strand on Higher Education Futures. She teaches design thinking to future teachers at the MA in ICT-Based Educational Design at Aarhus University and recently gave a workshop on valuebased vision-driven educational design thinking for educational developers at University College London. This spring she is invited to give keynotes at the dariahTeach 
conference in Lausanne on "New (infra)structures for the future university: beyond digitized higher education?", at the CHED2017 conference in Shanghai on "Teachers as Learning Designers: How to use Design Thinking to enhance students' experience and become more innovative in your teaching practice" as well as at the Playful Learning conference in Manchester on "Designing for playfulness in higher education". Recent publications within this field include "Academic Citizenship beyond the campus: a call for the placeful university" (2016), "Critical reflection and dialogical learning design: moving MOOCs beyond unidirectional transmission of content" (2017), and "Participatory Academic Communities: a transdisciplinary perspective on participation in education beyond the institution" (2015). 


\section{Abstract}

Distance education and e-learning has been around for some time now. The ubiquitous development of the internet (Sharples, 2007) has however made way for the emergence of new educational formats such as the much talkedabout Massive Open Online Courses (MOOCs). Within MOOCs users have access to educational literature and tasks everywhere and at all times, which allow users to fit the course into their own pace, place and Personal Learning Environment (Attwell 2007).

Today MOOCs have spread across the globe, and we now see institutions such as Aarhus University developing new interpretations of the MOOC format, however without the 'Massive' part (Aarhus University, 2016).

Over a 5 week period we conducted a netnographic (Kozinet, 2015) mixed methods research of the MOOC Blended Learning Essentials ( https://www.futurelearn.com/courses/blended-learning gettingstarted/2 ). Contrary to the acclaimed potentials of MOOCs, our research showed a pronounced lack of dialogue and a high degree of what Freire (1996) calls "the banking concept of education," entailing a high amount of one-way information transmission (Hoem, 2006). To circumvent these tendencies, the paper presents a case analysis and design framework for moving MOOCs beyond "the banking concept of education" and towards dialogue in ways that support critical thinking; a high-level cognitive skill essential to higher education (Laurillard, 2012).

\section{Introduction}

M00Cs originate from the distance education tradition, bearing many of the same potentials for providing education for people who doesn't have access or means to participate in formal education (Sumner, 2000). First generation of distance education started in the end of the 1800's with letter or correspondence education. In the 1960's came the second generation of distance education, which was the mass media mediated education. Third generation, which we are now in the midst of, is the computermediated education. In the end of the 1990's there was a big boom in eLearning, big consortiums were established, but many of these soon went bankrupt, as the eLearning wave never reached the popularity and penetration hoped for (Bang, 2006). In 2008 the first MOOCs, Massive Open Online Courses started to appear. Starting with a connectivist course on Canada's Athabasca University, MOOCs soon expanded and was embraced by other Universities, which saw the potential in opening up their classes and thereby promoting their universities (Haber, 2014). These first MOOCs, which was later titled cMOOCs, because they build on a connectivist theory of learning, which in practice encompassed learning in organic communities, provided by ICT solutions such as bulletin boards, chats and so on. Many of the later MOOCs, by other universities, was labelled XMOOCs, which stand for extended. ThesexM00Cs have been criticized for employing a behaviorist approach to learning, focusing on transmission of 
information, through videos, and adaptive test in form of multiple-choice tests, thereby employing outdated learning methodologies (Daniels, 2012).

Though many mutations of MOOCs have since appeared, ranging from synchronous SMOC's to collaborative DOCC's (Bang et.al., 2015), the x- and cMOOC categories are still the measure in which the learning design of MOOCs are normally categorized. Two radically different learning philosophies, one focussing on learning through collaboration and discussion while the other focus on transmission of information and learning through acquisition (Laurillard, 2012).

Society and businesses today are demanding more than just specialized formal knowledge from graduates (Laurillard, 2012, p. 12). 21st century skills, which also go by the name of higher cognitive skills, generic skills, or soft skills (Laurillard, 2012; Dalziel et. al, 2013), have come to be skills of great importance. These skills encompass the ability to cooperate, critical thinking, complex problem solving, multimedia communications and technological competencies (Laurillard, 2012, p. 12). Educating for such skills requires a redesigning of current 'banking concept of education' (Freire, 1974) MOOCs in order to change their learning design towards integration of skills with content knowledge (Dalziel, et. al, 2013).

In the Spring of 2016 we followed the course 'Blended Learning Essentials,' provided by the platform Futurelearn. It is a 5-week course aimed at teachers and covers approaches to and practices of blended learning in teaching. Here follows first a description of our methods of study and a short introduction to the field of learning design. Then a case description and analysis of the MOOC 'Blended Learning Essentials' (BLE) where we discuss how this particular learning design might be redesigned towards supporting the development of 21st century skills. In the case, our specific focus will be on developing critical thinking through dialogue. In conclusion we will, based on our analysis, give design suggestions applicable for developers and teachers that want to use MOOCs or similar online designs in their teaching and education.

\section{Method}

\section{Grounded Theory Method and Netnography}

We conducted our case research with a Grounded Theory Method (GTM) approach (Bryant \& Charmaz, 2007). GTM allows the researcher to take an abductive approach, coding empirical data and generating theory on the backdrop of this analysis (Bryant \& Charmaz, 2007, p. 156). Given that we wanted to examine 'Blended Learning Essentials' as a specific MOOC learning design this approach seemed more fitting than a hypothesis testing approach. Furthermore, based on the abductive approach, GTM allows the researcher to move back and forth between field and analysis, between data and concepts, and between testing the emerging understanding and developing new concepts (Bryant \& Charmaz, 2007, p. 1). In this regard the nature of GTM somewhat 
resembles the iterative nature of much design research, allowing a constant movement between induction and deduction (Brinkmann \& Tanggaard, 2015, p. 242).

Alongside GTM we also used netnography (Kozinets, 2015) as MOOCs are online and thus our data collection varied between different netnographic approaches. Our research was carried out online by 6 different researchers divided in two groups taking up different netnographic approaches, thereby creating investigator triangulation (Stake, 1995). This was done to heighten the validity of research where the different perspectives where used to nuance and compliment each other. Accordingly, one group took up an autonethnographic approach, to immerse themselves in the participants experience of the MOOC. The aim was here to get insight into the participants interactions and experience so as to describe the depth of the participants 'lived existence' in the MOOC (Kozinets, 2015, p. 258). The other group used a socalled symbolic netnographic approach, which are not focused on the lived experience of the individual in the MOOC. Here, attention is to a greater extent on the social interaction and social experience of the community obtained through a communication analysis. (Kozinets, 2015, p. 250).

After the first two weeks of the 5-week MOOC, researchers from the two groups met to discuss, code and analyse the empirical data across the data sets into categories using open coding (Brinkmann \& Tanggaard, 2015, pp. 247-51). The categories emerging across the six researchers' data sets were then developed, iterated and tested against data collected the remaining 3 weeks of the MOOC course. Following the completion of the MOOC a text mining (Miner et.al., 2012, pp. 3-91) research of the comment sections was made in order to quantitatively substantiate the validity of the emerged categories and codes of the qualitative GTM netnographic research.

\section{Text mining}

The text mining code can be found on Github here:

https://github.com/kimhaagenmathiesen/Creating-Dialogical-Elearning-inHigher-Education

Text mining is a methodology for analysing big amounts of texts quantitatively, it enables the researcher to handle very large corpuses of text, which the researcher normally wouldn't be able to handle with close reading alone (Miner et.al., 2012). The text mining was employed deductively and aimed to test the hypothesis emerging from the netnographic GTM: that there was low occurrence of dialogue in the MOOC. Using the text mining we were able to visualize the dialogue as a coherent whole spanning the entire MOOC's different comment sections. Something we could not have achieved the qualitative nethnographic tools alone.

The text mining was carried out with the programming language R. We manually copied the entire comment sections, consisting of 53 individual 
chapters, into a corpus of documents. Keeping the documents separate was done in order to be able to also access and analyse comment sections individually. The formatting of the text was rough, but had parameters which made it possible to search through both comments and replies, and also single out the comments that had replies. This was important, because it was only within these opportunities for dialogue would arise. Below is one example of this work:

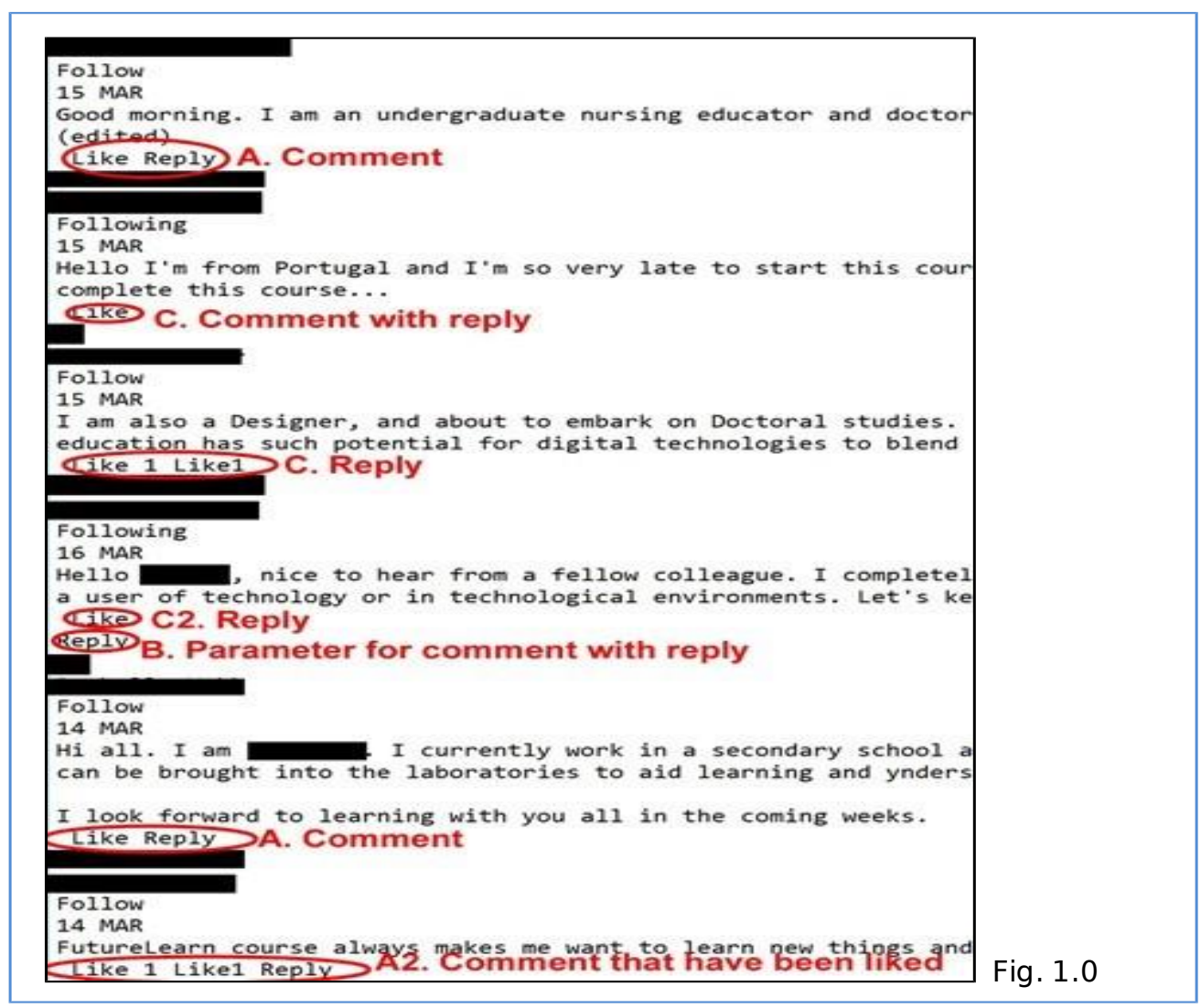

A Shows a parameter for searching comments, A2 show another parameter for comments. $\mathrm{C}$ and $\mathrm{C} 2$ shows parameters for searching replies. While $\mathrm{B}$ shows a parameter for searching actual comments that have been replied to. Therefore, C's need to be minus $\mathrm{B}$, as the original comment that is not a reply, will be counted as such. Counting B's will also provide a total count of threads with replies. A2 shows a problem because it has been "liked" and there will therefore be a lot of possibilities for how many times it has been liked. Preprocessing therefore needed to remove numbers. The documents contained 25 parameters that needed to be searched in total.

The text mining was done in two parts. The first part of the text mining searched parameters like the ones illustrated above in order to account for the amount of 1) 'comments,' 2) 'replies' and 3) 'comments with replies.' There were a total of 25 different parameters that was searched. These were searched across all 53 documents of the corpus and then put into a matrix. From here it was possible to generate variables for 'comments,' 'replies' and 'comments with replies.' From these variables we could then calculate what 
percentage 'replies' constituted when compared to 'comments' and what the average amount of 'replies on comments' amounted to when compared to 'replies.' Further we created a visualization showing the numbers of each variable over time for each comment section.

The second part of the text mining was done to get a clearer idea of each individual participant's communication pattern. By searching the position of the words "Follow", "Following" and the name "anonymised" and then minus the position with one we got the names of all participants in the comment sections. anonymised was searched because we had participated nethnographically in the MOOC and those comments therefore didn't have the "Follow" parameter on them. Because names occurred twice due to the formatting of the comment section, this workaround was possible and because we searched the other names by position we didn't get double occurrences of their names. When we had the names it was possible to arrange them in a table, and sort them decreasing, getting the number of occurrences for each name, corresponding to each time that particular participant had commented. By doing this we could then count the total amount of participants active in the sections and visualize how many times each participant commented in total. Consequently, given that we had the names and comment count for each participant we could also find top 10 commenters or commenters that had commented for example 5, 10 or 15 times. By using a matrix and searching these names it was possible to create e.g. visualizations of the top 10 commenters' comment patterns over the 53 sections and of commenters commenting 16 times over the sections.

\section{Data set}

The data set of the netnographic GTM analysis of the Blended Learning Essentials MOOC consists of 34 screen dumps and 107 pages of field notes, containing both netnographic jotting and reflective notes (Emerson et.al, 2011). While the data set for the text mining of the MOOC consists of 53 unique comments sections in rough txt format.

\section{Ethical considerations in researching M00Cs}

New types of online interaction creates new opportunities for research but also creates a need for new research techniques and methods which again proposes new challenges in regards of applied ethics in research (Kanuka, 2007 p. 4). The ethics concerning the gathering of data in online contexts such as MOOCs are a contested area and especially the question of the requirements and levels of informed consent when researching publicly available material online is a matter of debate as the internet is neither public or private but rather "publicly private" or "privately public" (Kanuka, 2007 p. 10).

In regards to the ethical concerns in researching this particular MOOC a teleological approach as stated by Kanuka and Anderson (2007 p. 3) is 
the base of our research. The information provided by the participants through comments and replies in the MOOC are considered public-nonsensitive information (McKee, 2009 p. 11) and thus it does not require informed consent from the participants. We have however still taken precautions to ensure the anonymity of the individual participants in the MOOC by stripping names, gender and other personal markers of identification that could potentially display of specific individuals participating in the MOOC. That being said we are aware that our research is conducted without informed consent and that this is a matter of ongoing debate amongst researchers (Kanuka, 2007; McKee, 2009). Furthermore we are aware that the responsibility of securing the anonymity and the personal information provided by the participants through the MOOC entirely fall upon us as researchers.

\section{Teaching and Learning Design}

In her book Teaching as a Design Science (2012), Diana Laurillard apply iterative processes and design patterns to teaching and learning, which wealso find in other design sciences. She employs a designerly approach to teaching and learning to build tools, patterns and designs for practitioners in teaching. (Laurillard, 2012, pp. 211-226). Following Laurillard's approach in MOOCs enables designers and teachers alike to include the advantages we see in other design oriented practices where the professional community builds on the knowledge of others in order to create and develop a shared knowledge base (Laurillard, 2012; Laurillard, 2008). In the ever-changing and developing technological landscape within education it is a necessity to find flexible and adjustable ways of developing the teaching profession and practice. Framing the designer and teacher as 'capturing pedagogical form' through action research (Laurillard, 2008) and design-based research (Andersen \& Shattuck, 2012) might pose ways to integrate this changing landscape in valuable and meaningful ways within learning designs such as MOOCs.

Laurillard proposes using pedagogical patterns to enhance the exchange of knowledge, building on effective patterns within the profession. These patterns have affinity to design patterns but build on and integrates learning theory rather than (only) design theory. In this way a learning design framework is developed that enables teachers to develop, share and reuse educational designs and thus make it easier to copy and share examples of good teaching. Dalziel et. al (2012) compares it to the notational system used by musicians where the purpose is not only to recapture the complexity of an art in a simple system but also enable redistribution of this to others (Dalziel et. al., 2012, p. 3-4). The concept of Learning Design has it origins in four different projects from the beginning of the 2000's; the EML, SoURCE, AUTC and LAMS (Dalziel et. al., 2012, p. 5). What brings these projects together is that they are all focusing on the integration of technology in teaching processes. Learning Design is a descriptive framework and not a traditional pedagogical theory. It is to be considered pedagogically neutral and thus it applies to and are able to integrate different styles and pedagogies in teaching (Dalziel et. al., 2012, p. 13). Overall, Learning Design can be divided into three categories: 
- Learning Design Conceptual Map (LD-CM) that describes the overall lines of the learning design, what could be said to be a meta-perspective, combining core concept of LD-F with the wider educational landscape.

- Learning Design Framework (LD-F) that presents the framework for describing teaching and learning activities.

- Learning Design Practice(LD-P) that describes the everyday practice of the educational professional as she or he uses the LD-CM and LD-F tools (Dalziel et. al., 2012, p. 32).

Pedagogical patterns operate on the level of LD-F providing LD-P tools for professionals, these tools however overlaps with the LDCM, both including pedagogical approaches and description of the teaching cycle.

In this article we will use the pedagogical patterns to describe LDF on a session level of granularity (Dalziel et. al., 2012, p. 14) and we will use the conceptual map by Dalziels et.al (2012) to describe the overall learning design (see fig. 1.1).

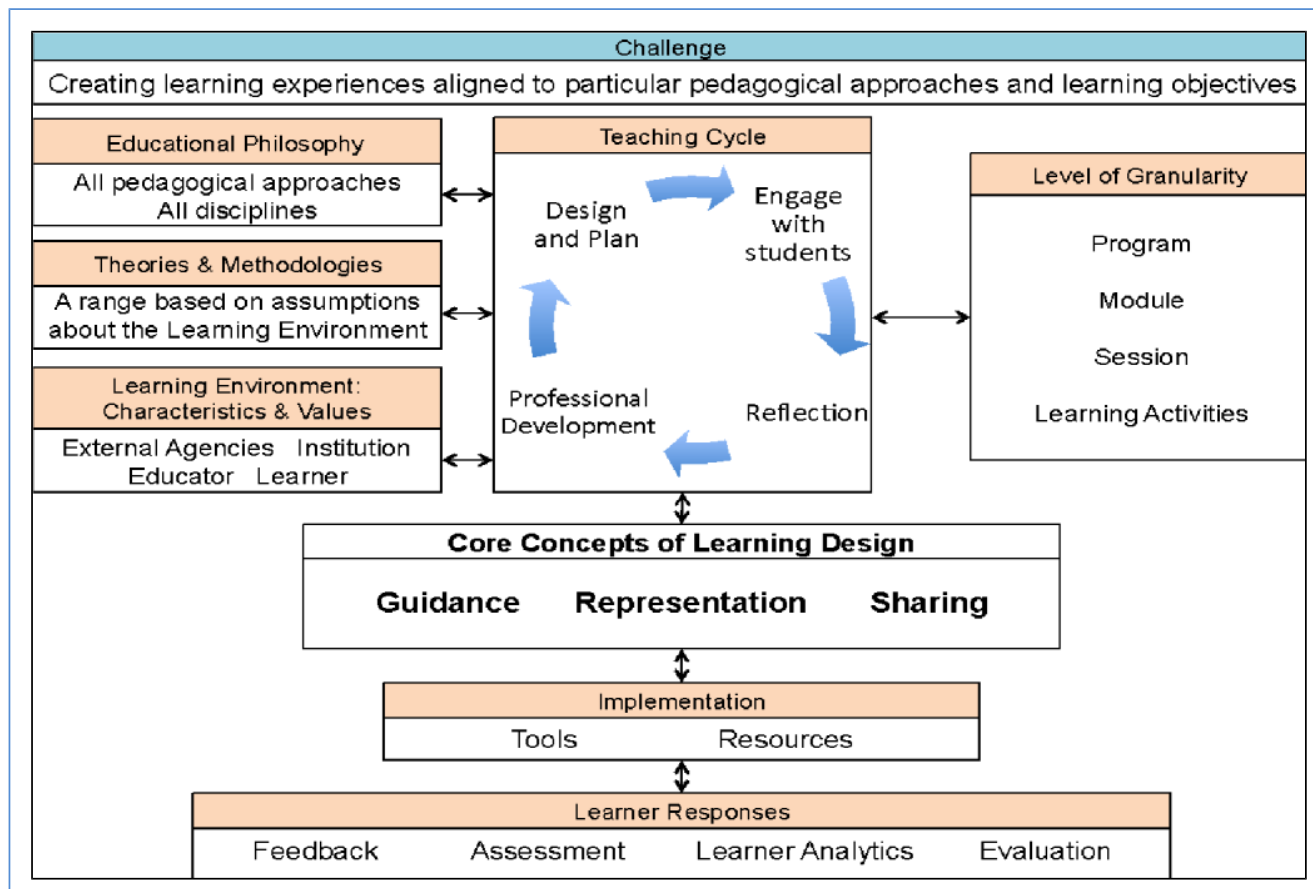

Fig. 1.1 Dalziel et. al., 2012, p. 14

\section{Case description}

When looking across the data sets, the most significant categories that emerged from the GTM examination of the MOOC were 'dialogue,' 'educational design' and 'critical comments'. These 3 categories persisted to be important following the deductive test against data the last 3 weeks of the MOOC. In the following, we will show that these three categories, which emerged from the empirical data, are heavily interrelated and intertwined. Furthermore, the category 'dialogue' was also deductively tested after the end of the course with Text Mining. 
GT category - Educational Design

The MOOC 'Blended Learning Essentials' (BLE) which has been the subject of our fieldwork is a MOOC offered by the platform FutureLearn (FutureLearn, 2016). FutureLearn is a company owned by The Open University in Milton Keynes, which since 2013 has offered MOOCs with different content through the learning platform. As other major MOOC companies, FutureLearn cooperates with various universities worldwide. Somewhat atypical for MOOC providers they also cooperate with a number of British cultural institutions such as the British Museum. BLE ran over five weeks (7/2-16 - 10/4-16) and was designed by Diana Laurillard, Professor of learning with digital technologies, University College London and Neil Morris, Chair of digital learning, the University of Leeds. BLE addresses practitioners in the educational sector, and deals with the subject of 'Blended learning' - something Günther (2005) describes as teaching methods and practices, which blends traditional teaching with the use of ICT or Internet-based teaching methods (Günther, 2005).

BLE consists of 5 weeklong lessons (modules

granularity level, fig. 1.1). The week.modules in the course contains a number of steps (session granularity level, fig. 1.1) that includes articles and videos that present the learning material, followed by an invitation to discuss in the comment sections. All of this can be viewed as learning activities on the level of granularity (see fig.1.1). Each module includes a collaborative exercise where the participants are invited to comment on the contributions of other participants. It also contains a final exercise, which, is a preprogrammed quiz / multiple-choice test with questions related to the lesson content. Furthermore, the MOOC invites the participants to use Twitter and tweet with the hashtag \# FLble1 to share experiences related to blended learning.

The page itself consists of a top bar that is connected to the user profile. Here the user can access different sub pages providing information of relevance to the user. Fig. 1.2 shows an overview of the web page with an active comment section. 


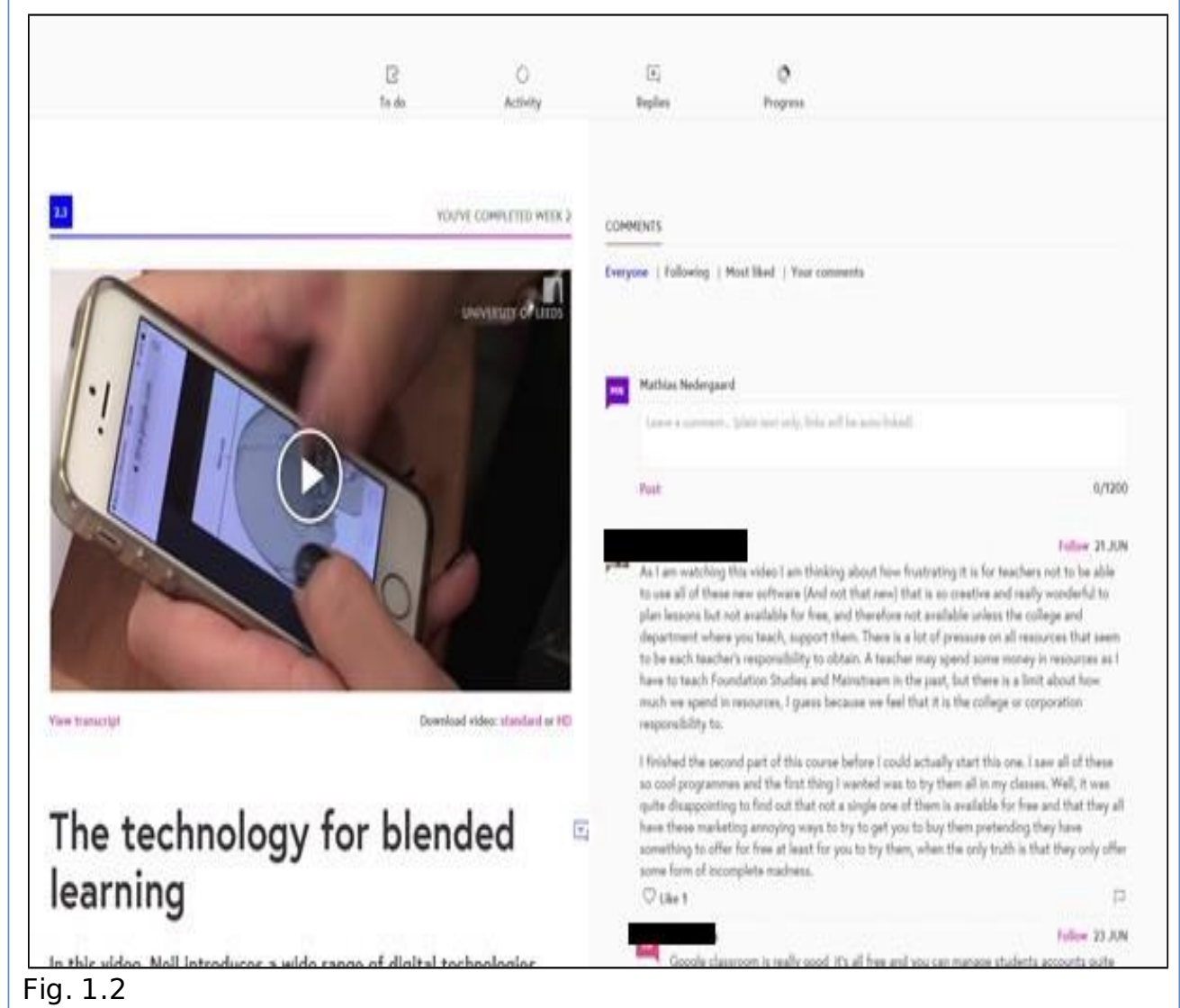

Fig. 1.2

The first of these subpages is called 'To do' (fig 1.3) showing the different parts of the course and which parts have been marked as completed by the user in order to track his or her progress in the MOOC. The example below shows a user who has completed the two first weeks and is currently at the beginning of week three indicated by the magenta square covering 3.1. 


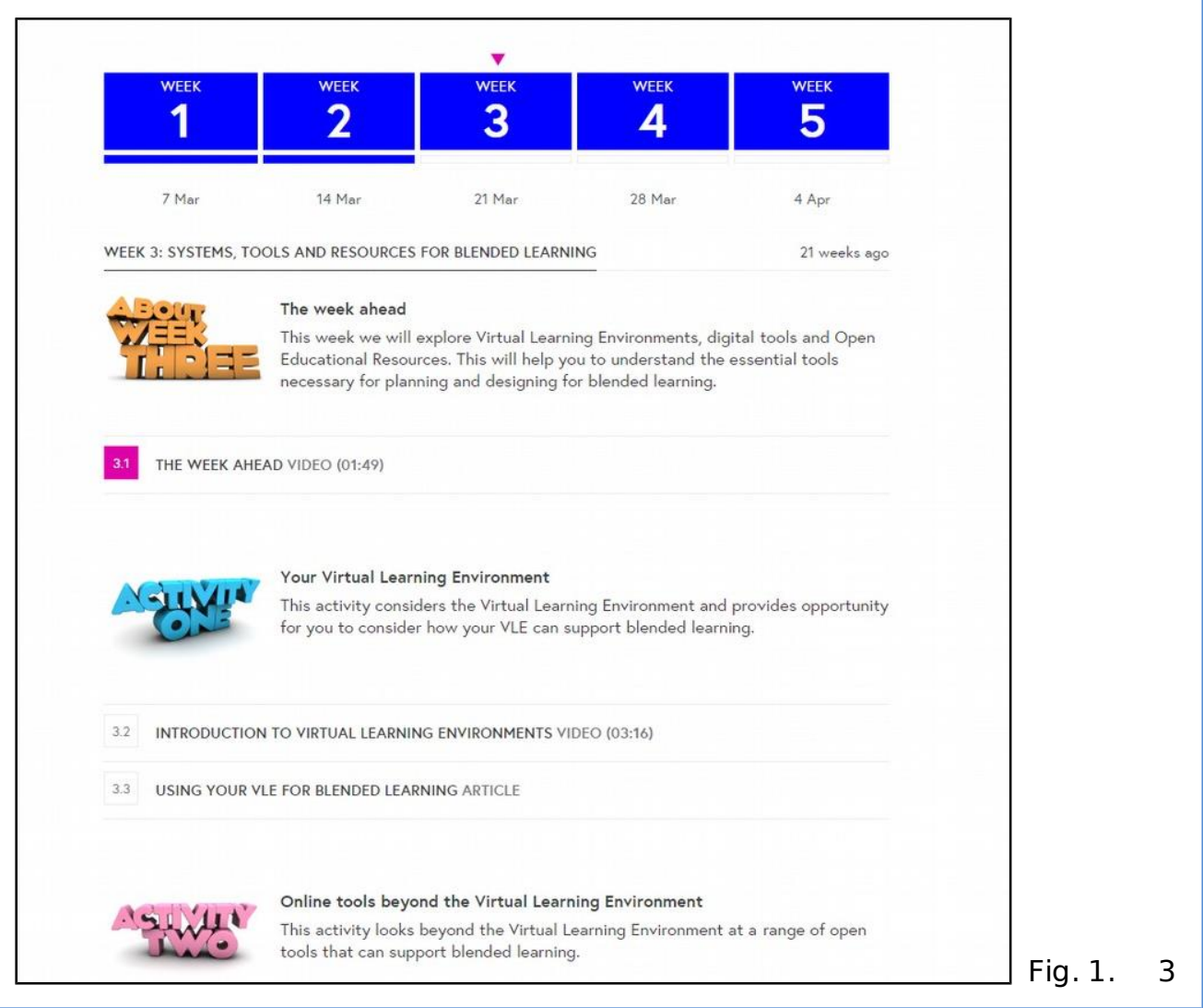

The 'Activity' subpage (Fig 1.4) shows recent activity from other users attending the course. These activities can furthermore be divided into three subcategories; 1) Everyone, 2) Following and 3)Your comments.

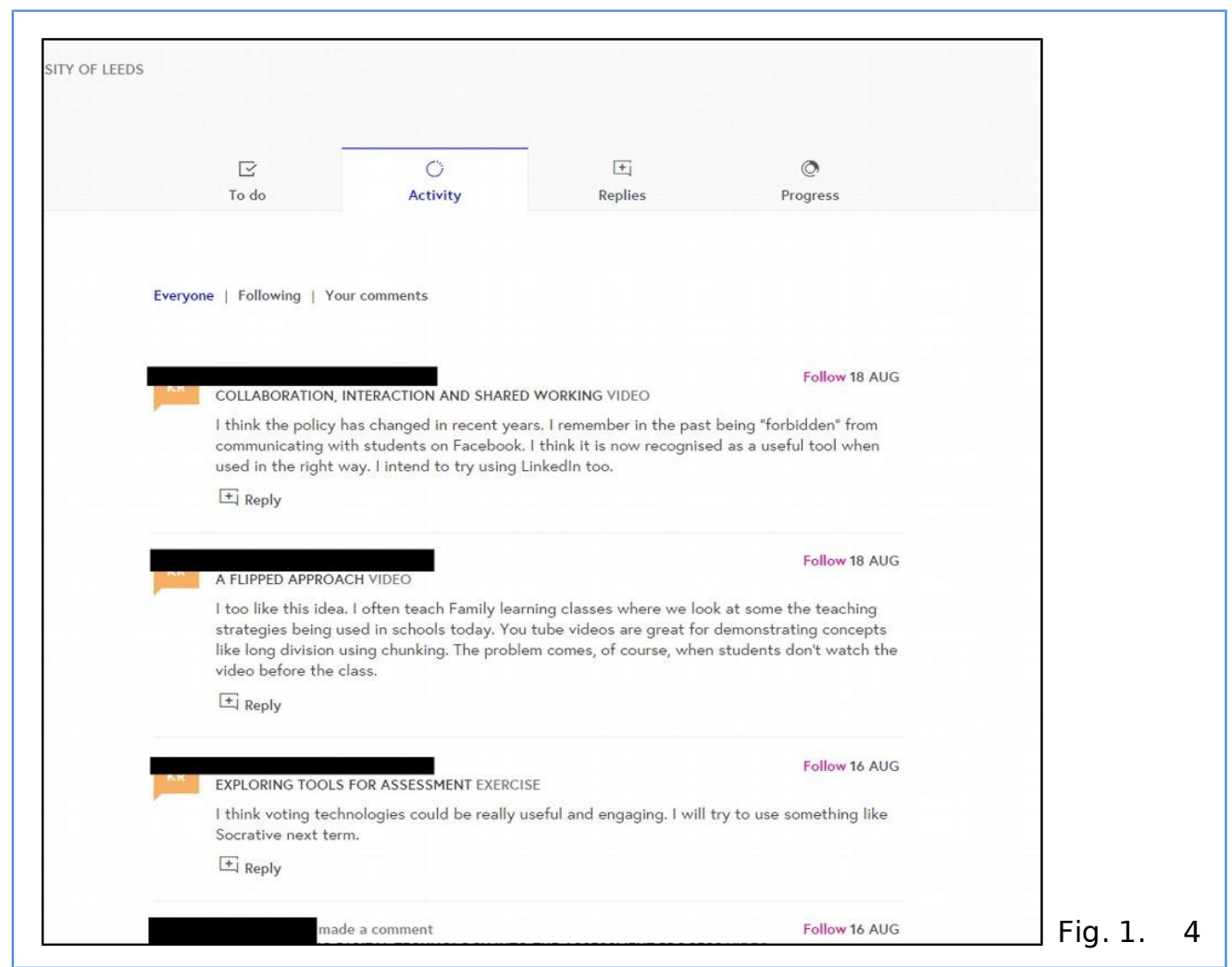


The next sub page is 'Replies' and is used to show the replies from other users to your comments, but this function is no longer available. However, you can still see the replies in the previously mentioned subpage 'Activity.' The last subpage 'Progress' (Fig 1.5) shows a percentage of steps completed and gives the user the opportunity to jump directly to the 'End of course test' finishing the course. Also, there is a link to purchase a certificate showing that the user has participated in the course as well as including the results gained from the course in the final test. To buy a certificate you need to have finished at least 50 percent of the course and completed the 'End of course test.'

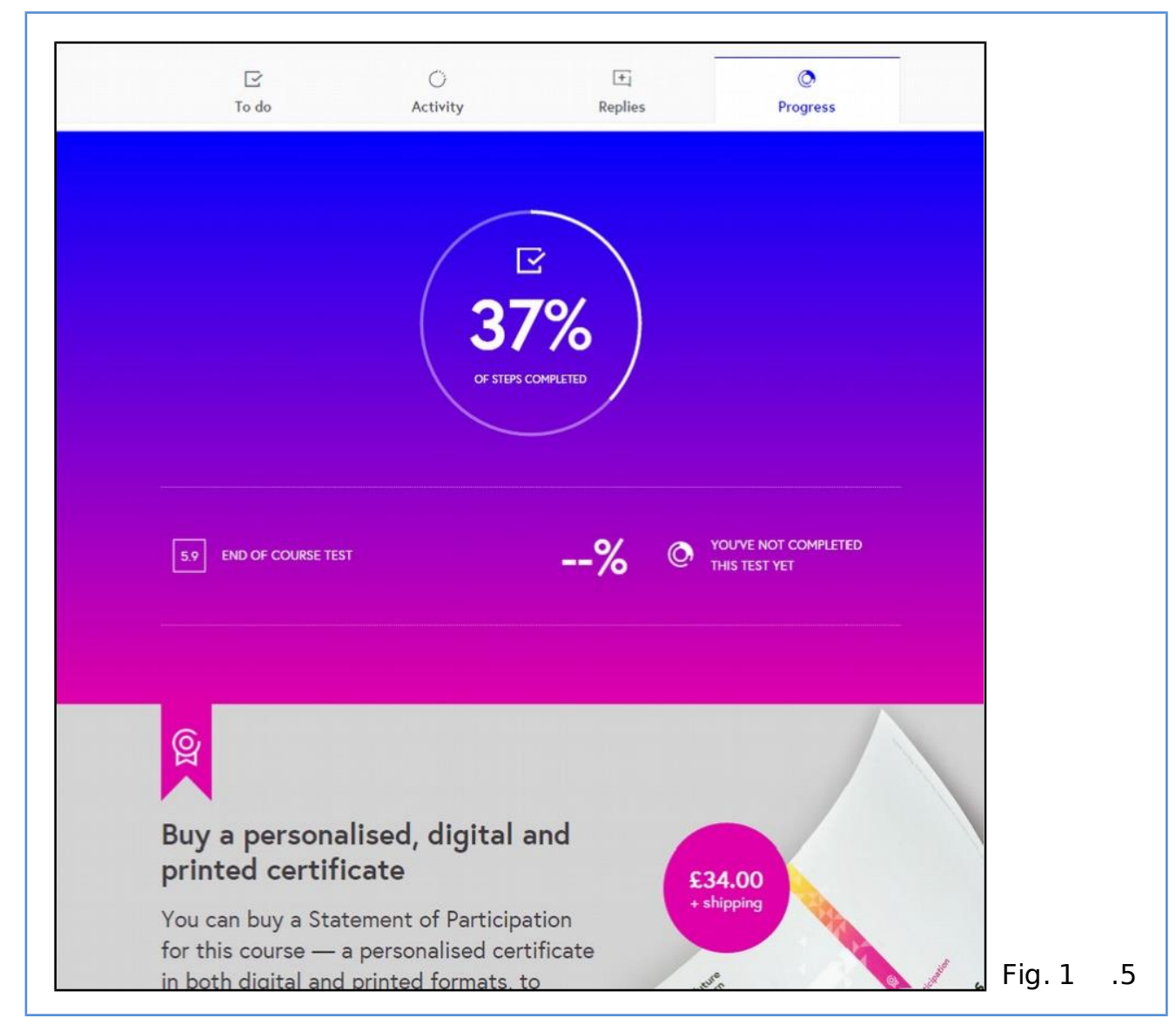

According to the team behind BLE this course is specifically directed towards teachers in further education, skills training, vocational education, workplace learning, lifelong learning or adult education. They state that the course will enable participants to understand the benefits of Blended Learning and take advantage of them to make more effective use of technology to support their learners.

In the first general video introduction to the course it is mentioned that the course will offer a professional community to work in. A community of blended learning practice that will be an invaluable source of information, knowledge sharing, and creative ideas. Furthermore the participants are encouraged to engage in the discussions throughout the course. The conceptual map (fig. 1.6) shows the course BLE inserted in a 
Learning Design. It is this Learning Design of the BLE that the analysis presented in this article focuses on.

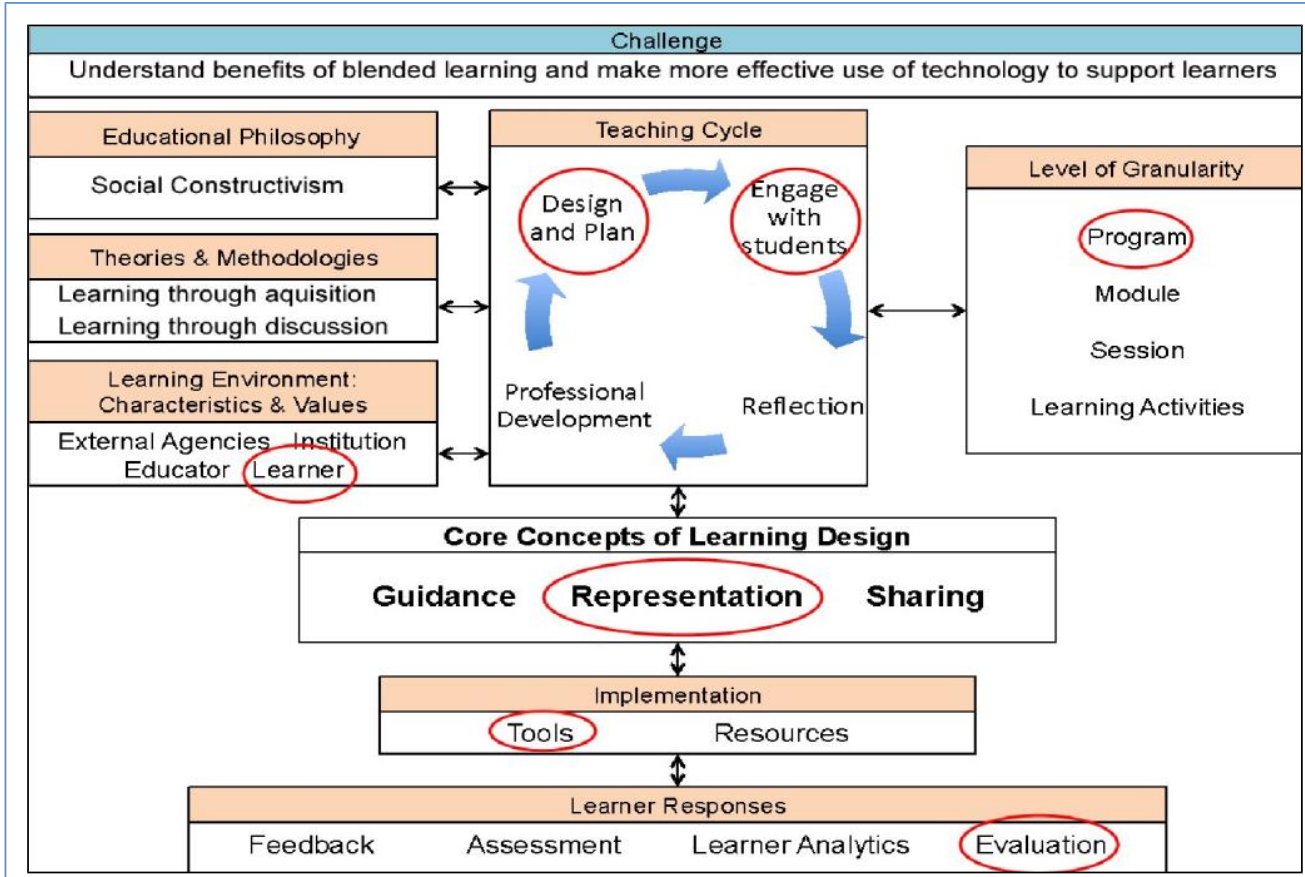

Fig. 1.6 Dalziel et. al., 2012, p. 14

\section{GTM category - Dialogue}

As mentioned earlier our nethnographic GTM and symbolic nethnographic examination of the MOOC, BLE showed a distinct lack of dialogue in the comment sections of the MOOC. This was however difficult to clearly document qualitatively. Yet, the text mining confirmed the emerging category we saw showing low dialogue in the MOOC. Overall we saw a total of 907 different persons active in the comments sections. In total only $18,34 \%$ of the comments received replies and in average these had 1,8 replies to them. One of two primary teachers of the course, Neil Morris, states in the comment section that the course has over 6000 participants, with $50 \%$ engaging with the content in one way or another. See fig. 1.7 below.

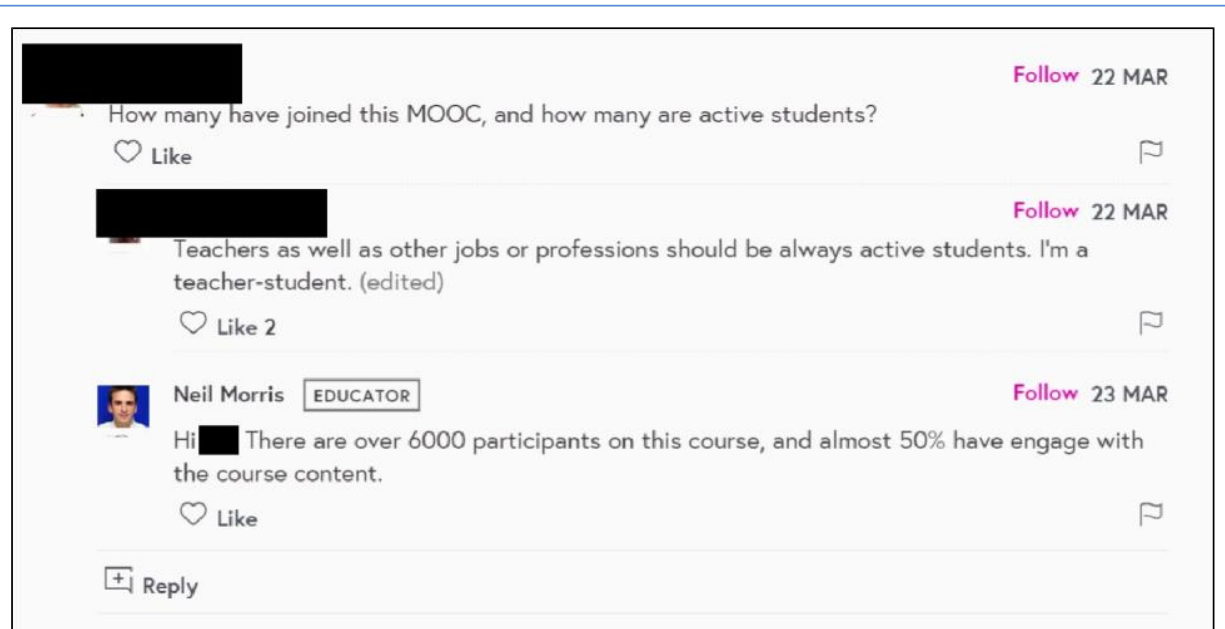

Fig. 1.7 
Assuming 3000 participants engaging with the material, that makes only 30,2\% of these participants active in the comment sections. Of the total participants, 6000 , this would be only $15,1 \%$ active in the comment sections. Figure 1.8 below shows how 'replies,' and 'comments with replies' to them are a relatively small part of the entire amount of comments. Further it shows that comments fall drastically over time, which corresponds to the low completion rate in MOOCs in general of 15\% (Jordan, 2015).

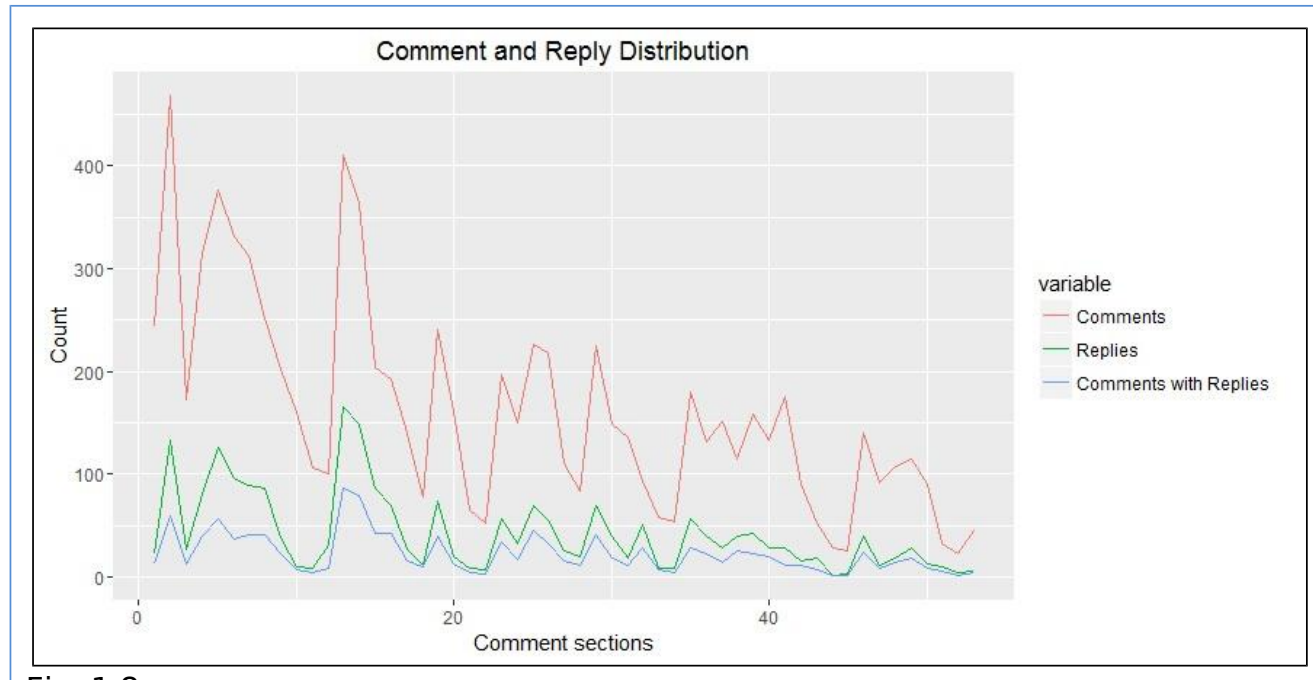

Fig. 1.8

Taken together, these numbers and the visualization suggest that there is an overall poor dialogue in the MOOC. The average of 1,8 replies per comment with reply would suggest that there was almost no actual dialogue happening in the MOOC. However this is of course an average number and we knew from our netnographic participation that some comments had a lot of replies and many just one, making the average number only an indicator of low dialogue.

It was also very likely that there was a great difference in relation to the extent that particular participants commented. Further the text mining showed that there was a relative small group who commented a lot while the majority of participant commented very little. See fig. 1.9. 


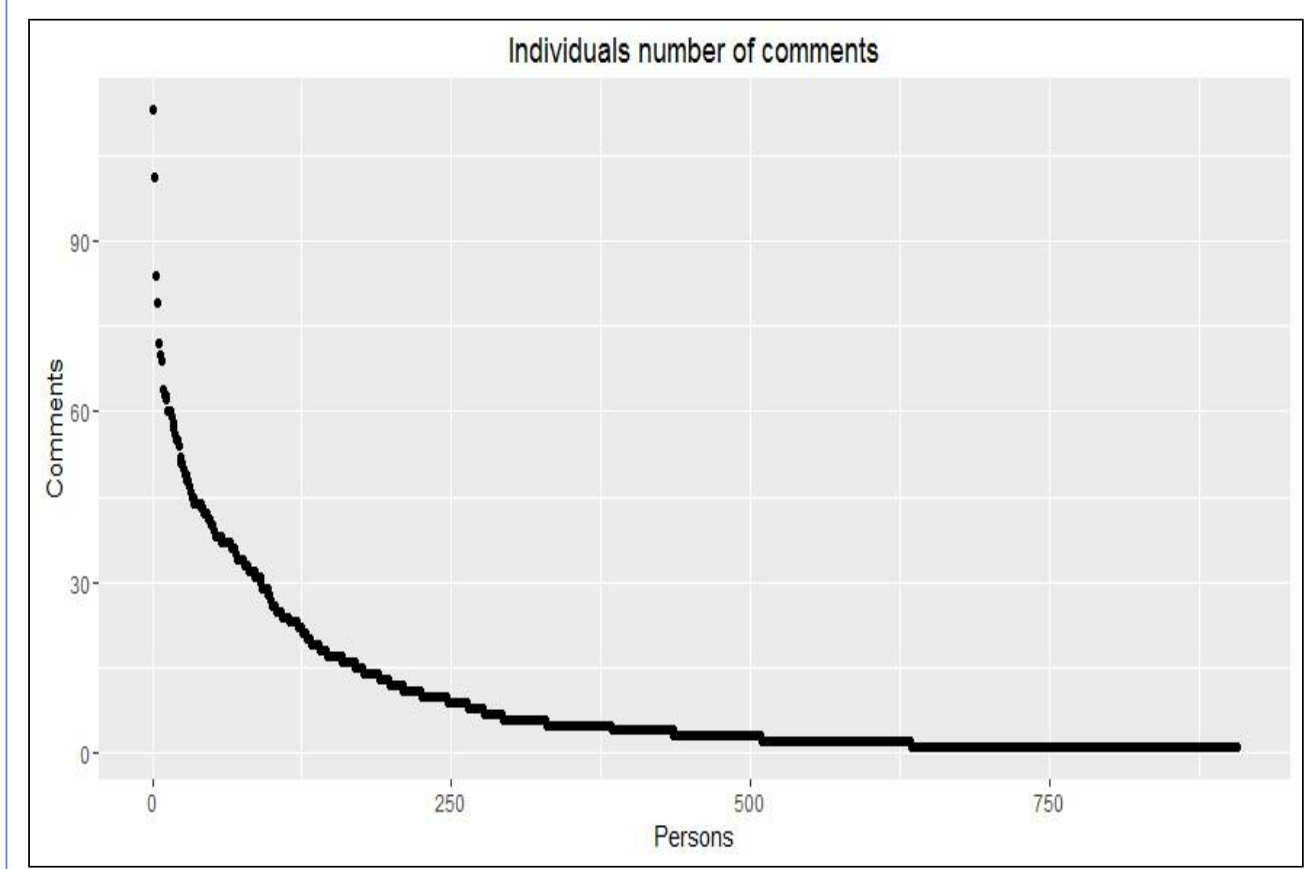

Fig. 1.9

The above graph shows each participant in the MOOC and how much they comment, the graph seems to follow what might resemble a power law curve. The graph has a rather long tail and we can actually calculate that 524 people comment under 5 times over 53 sections. These are participants who can be documented to not being part of any real dialogue throughout the course. This, however, also opens up for the possibility that a little group of participant comments enough to actually obtain dialogue in the MOOC. Looking deeper into the top ten commenters in the MOOC (see fig. 2.0 below), we can more clearly see how their communication is confined to specific sections, which might actually point towards that they are involved in some kind of dialogue in these specific threads. This is interesting, because it shows that they do not have an evenly distributed comment pattern where they e.g. comment a couple times in each section, but rather communicate a lot in specific sections and stay silent in others. 


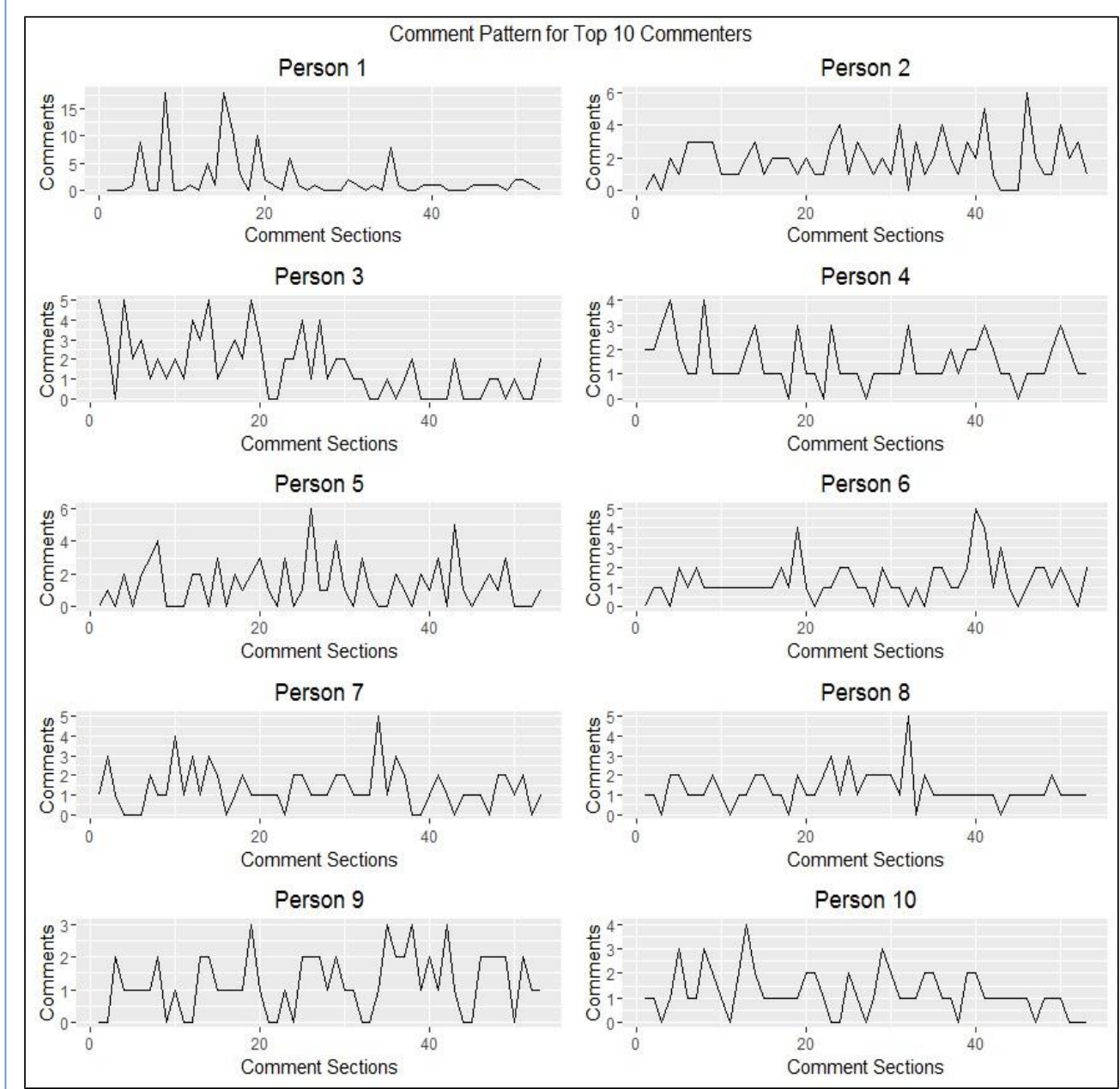

Fig. 2.0

The above poses the challenging question: Where to cut the curve in fig. 1.9 and say that beyond this point participants are not dialoguing but rather (if commenting at all) talking into empty space. In other words, what is the range where comments and lonely responses are transformed into dialogue and possibility for an emerging community of practice. Looking at the graph the rise in the MOOC seems to start at a little under 20. Fig. 2.1 below shows 10 participants commenting at least 16 times over the comment sections.

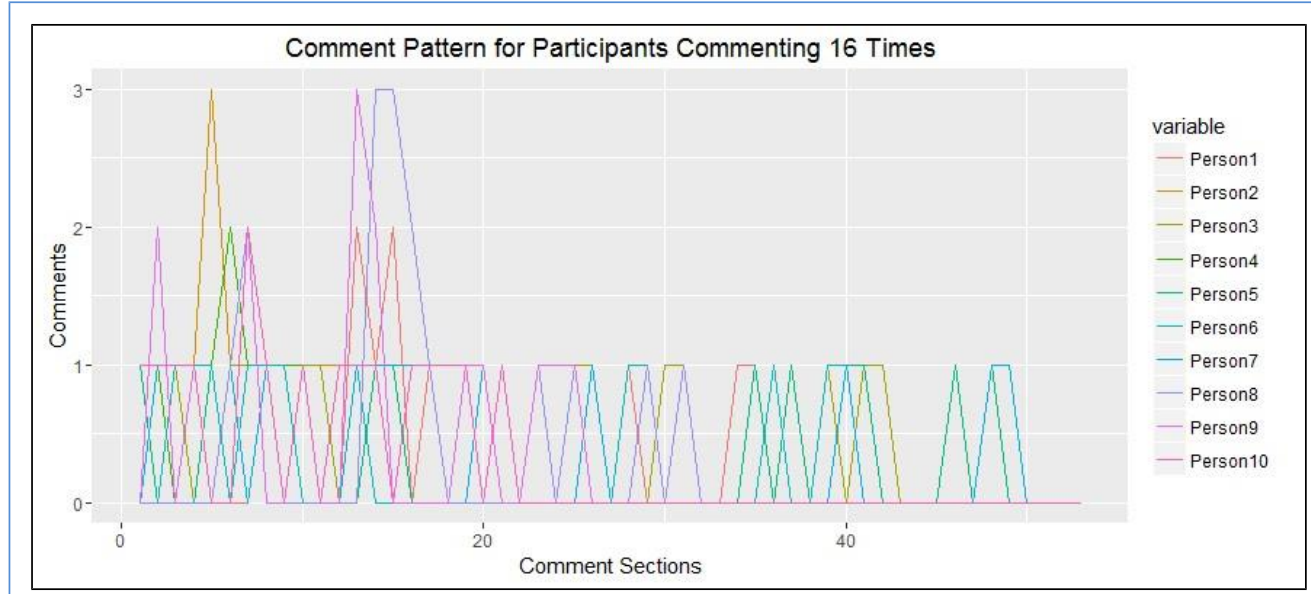

Fig. 2.1 
Here we actually see participants initially commenting 3 times and then abstaining from commenting more than once in a while posting a single comment in specific sections after that. This might indicate one beginning dialogue of 3 turns, but not enough to form a community of practice over the course of the MOOC. This indicates that the curve might have to be cut even higher, leaving the group of potential dialoguing participants even smaller. If we cut the curve at 16 comments it would leave 158 participants commenting more than 16 times amounting to $17.42 \%$ of the participants active in the sections commenting more than 16 times.

Thus, we clearly see that the general social interaction in form of dialogue is very low. $18,34 \%$ of comments received reply with only an average of 1,8 replies. However we see a pattern of active participants commenting a lot in specific sections, showing a pattern that point towards them engaging in actual dialogue. This is rendering the average reply per comment a bit redundant. This shows that although we have a relative small occurrence of dialogue, we have a small group achieving this throughout the course, supporting that these could actually participate in a community of practice. It does however seem unsuccessful that under 158 people, out of 907 people active in the comment sections, achieves this pattern at any time during the MO0C, with 524 people commenting less than 5 times over 53 sections. Looking into those potentially dialoguing 158 participants compared to the total of 6000 participants, the establishment of a community of practice seems even more unsuccessful, with only $2,68 \%$ of the participants achieving what could be described as a beginning dialogical pattern in their comments and replies.

The lack of dialogue in the above could be said to align with the study in 'Deconstructing Disengagement: Analyzing Learner Subpopulations in MOOC's (Kizilcec, Piech \& Schneider 2013), where they establish 4 different participant clusters;

1. Completing (attempted all assignments),

2. Auditing (Infrequent assignments, watching videos),

3. Disengaging (starts doing assignments, disappears or watches video infrequently)

4. Sampling (watches one or two videoes).

Using these 4 participant types on the BLE MOOC might explain why only $50 \%$ of the total 6000 participant engages in course material - these could be characterized as sampling participants. Furthermore, it might explain why we see a dramatic drop in comments during the course - this could be from disengaging and auditing participant. Importantly, the above study measures the engagement of participant based on assignment completion and video viewing, whereas we look for dialogue in the MOOC. Consequently, the participant types fall short in describing the comment behaviour in the MOOC as they only focuses on the work of the lone individual. It might therefore be useful to supplement the study with more collective participant types based on e.g. dialogical or collaborative engagement in the MOOC. Here we have 5093 
participant not engaging, 907 active in the sections and of the only 158 reaching dialogical comment patterns. Taken together, this leaves us with three general participant types, see fig. 2.2 .

\begin{tabular}{|llll} 
Participant types Comment \\
based on \\
pomment
\end{tabular}

Fig. 2.2

Building on the premise established by the MOOCs learning designers: that the community of practice is one of the most important tools for learning in this course, then the learning design seems rather unsuccessful in supporting and promoting participants to building dialogical patterns and communities of practice among them in the MOOC.

\section{GT category - Critical Comments}

This category emerged when one of our researchers focused on the presence of critical comments in the beginning of the MOOC (Fig. 2.3), we therefore kept observing if this phenomena would appear again during the course. 
....few are decidely critical - I'm going to take som screenshots of the critical comments - that's what's most exciting. -Lærke, Week 1

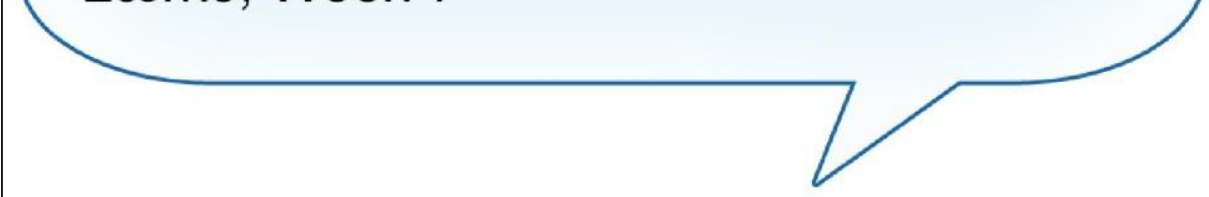

Fig. 2.3

Sadly, the phenomena turned out to be a lonely Black Swan (Kozinets, 2015, s.163). However, it made us aware of the deafening silence of critical reflection and dialogue in the MOOC. Coupled with the very low occurrence of dialogue and the lack of supportive educational design this added up to point towards some distinct flaws in the learning design of BLE.

\section{Blended Dialogue Essentials}

Dialogue can occur in several different ways and through various media and communication channels; we can talk to each other verbally, we can write and read messages to each other, we can gesticulate different meanings or intensions through our movements and much more. The language can thus be viewed as a tool to communicate meaning or understanding to others and just as important, to negotiate meaning and understanding amongst people in a community. Language is also used when systematizing and categorizing thoughts, building up arguments, and expressing learning and knowledge. Somewhat simplified, knowledge is created in negotiation through the use of language with others and it is stored in memory in linguistic systems. Thus communication amongst people occupies a meaningful and central role in learning (Imsen, 2006). According to Bruner language and thinking is inextricably linked and it is through language that we are able to think abstractly, independently and critically (Imsen, 2006).

Therefore, communication in the form of dialogue amongst participants is crucial when it comes to creating more complex knowledge structures, which are particularly evident when older children and adults need to learn. In continuation of this, Bakhtin points out that dialogue, which can be viewed as a linguistic exchange between two or more parties, is characterized by the parties' attempt to approach each other in a conversation, making "... Any true understanding is dialogical" (Imsen, 2006). This is also echoed in Paulo Freire's work. In the 1970s Paulo Freire criticized the educational system in South America for bearing resemblance to a bank where the teacher inserts transmitted knowledge into the students heads in the same way as one would insert money into a bank (Freire, 1996, pp. 52-67). This, which he called 
Banking Concept of Education, leads to superficial and repetitive learning outcomes where the student only learns how to reproduce the transmitted knowledge of the teacher, but do not know how to create any new knowledge for himself. In this way, students only become able to adapt to the already existing and doesn't become able to transform it (ibid.). Through the banking concept of education, teachers (or learning designs) end up oppressing the students in the sense that they never become aware of their own situation or become able to act on it (ibid.).

The solution for overcoming this form of education is, according to Freire, to create integrated knowledge trough dialogical education (ibid.). Through democratic communication, which must be dialogical, between teachers and students, it's possible to establish what Freire calls Conscientização, that is, critical consciousness, making the students aware of their own situation and allowing them to critically reflect over the world and what is learned - and thus become able to transform it (ibid.). Freire's notion of critical consciousness is comparable to Laurillard' notion of critical thinking, a core part of 21st century skills. (Laurillard, 2012, p. 12). Inthis way, critical dialogue enables teachers and students to move towards collective reflection of the learning object (i.e. blended learning), through both learning from each other and reflecting together through dialoguing (ibid.).

According to Freire, the word (dialogue) is what enables humans to transform the world (Freire, 1996, pp. 68). But in order for this to happen, the word is dependent on both critical reflection and reflective action, which merges into what Freire, calls 'praxis' (Freire, 1996, p. 70). In this way, humans are through dialogue with each other able to create unified action and reflection which becomes a united praxis in the world (ibid.). All this is however only possible if teachers and students engages in democratic dialogue with each other, transforming their world and humanizing it (ibid.). In the banking concept of education, this is however far from the case. Here the teacher transmits the world to the student (which then never become part of it), and denying the students interaction with both the word and the world in the form of praxis (Freire, 1996, pp. 52-67). The differences in these two forms of learning designs is illustrated below. 


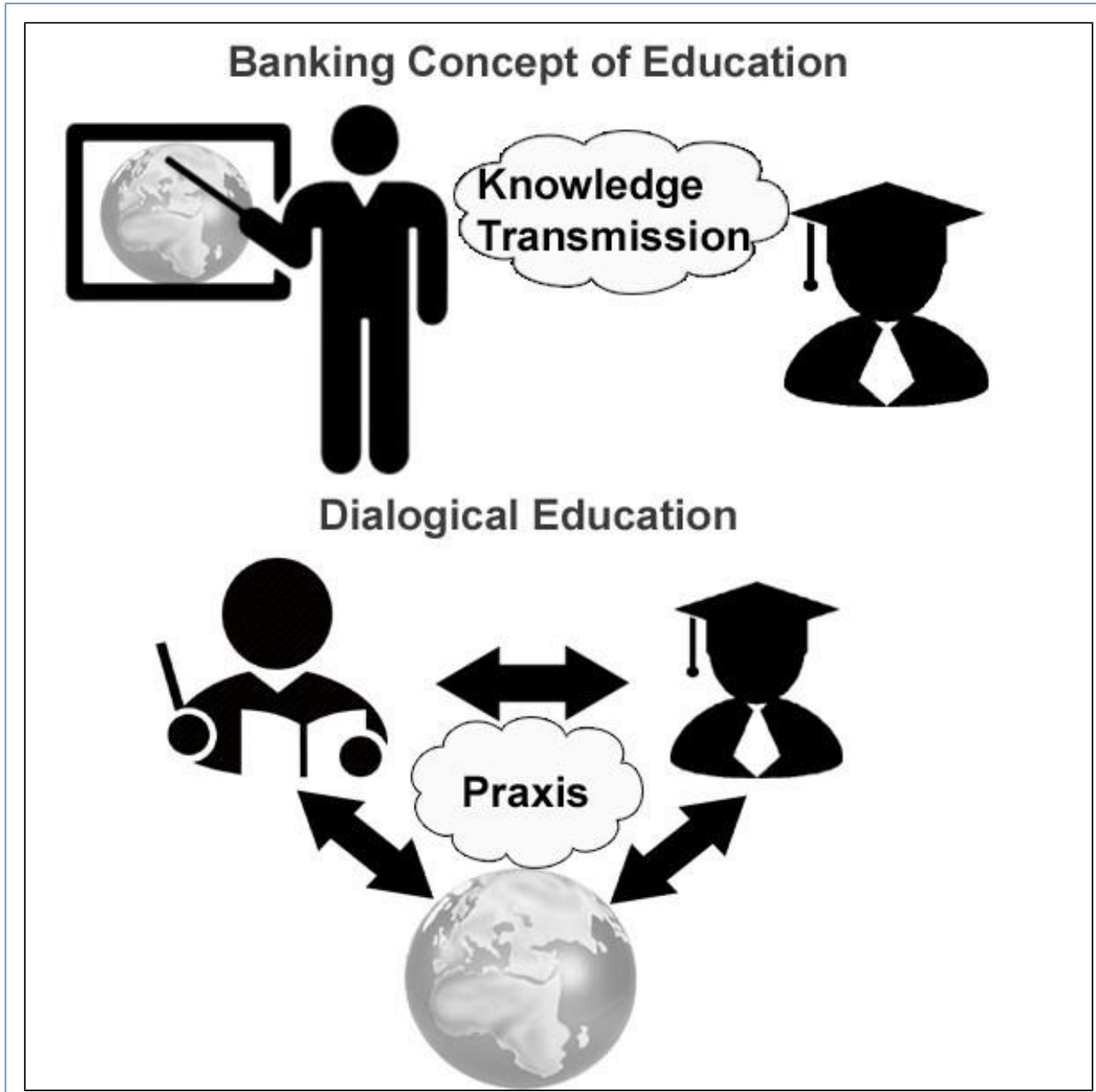

Fig. 2.4

When we look at the categories that emerged from our examination of Blended Learning Essential through the lens of the above, it becomes clear that the MOOC's vast amount of video transmitted teacher lectures, multiple-choice tests and instructional design makes for a learning design that rather clearly resembles The Banking Concept of Education. Here, there is no room for democratic dialogue, critical reflection or integration of knowledge in a shared community of teachers and students. The videos have a uni-directional transmitting communication pattern (Hoem, 2006), clearly resembling the insertion of transmitted knowledge into the student that Freire (1996) describes. Furthermore, the multiple-choice test doesn't support or encourage critical thinking, participatory construction of knowledge, reflection or dialogue about the learning subject or covered topics, but rather tests that students have memorized the transmitted inserted knowledge. Yet, BLE tries to circumvent this by appealing trough putting it onto the shoulders of participants to establish a community of practice in the comment sections and creating a dialogue here. This is however, to say the least, unsuccessful. One clear reason for this is that it is not in any way an integrated part of the learning design, but only put forward as an optional invitation. The appeal is not integrated and as such the burden is on the students to create dialogue against the system of the learning design. As we have shown, only a small part of 
participant reach a dialogical comment pattern and we see a distinct lack of dialogue looking at the comment sections as a whole. In this way the connection between students and between students and teachers are cut, which inhibits them from achieving a dialogical connection and thereby a united praxis.

Thus the learning design of the MOOC replicates a form of the banking concept of education that is almost antidialogical, causing silence amongst the students and absence of the teachers. As dialogue is an inherent requisite for developing Conscientização or critical thinking, we get a learning design that fosters a lack of critical thinking and reflection in the comment section, resulting in the category 'critical commenting.'

When the goal is to support and promote learning

through critical reflection, this must necessarily also be at the heart of the learning design. Therefore, it is important for educators beyond mentoring and supporting the learners in the dialogical learning to also consider this in the organization and design of education focusing on making it dialogical. Olga Dysthe (1997) suggests that this can be done through 'authentic questions' and 'high valuing.' Authentic questions can be characterized as similar to open questions and does not have only one answer. Further, the purpose of the authentic questions is not to check if the learner has learned a previously given fact or information, but rather to gain insight into the learner's understandings, interpretations and reflections. An example of an authentic question might be "What do you think is meant by X?" where the answer cannot be found elsewhere and the students are thus forced to critically reflect and engage in a dialogue. "This type of question presupposes that students think and articulate insights and understanding which can be flawed. But it is important to get the thought process started, then the understanding is increased" (Dysthe, $1997 \mathrm{p}$. 226). Authentic questions thus become central in a dialogical teaching where it is not just about reproducing transmitted knowledge but about creating shared knowledge. High valuing is about recognizing the contributions of the students; at the lowest level to praise it and at the highest level to involve the student's contribution, and ultimately change the content of the teaching on this basis. In continuation of this Dysthe says: "Any real dialogue never arises in a class unless the teacher sees the student as a source of knowledge and takes the student's response and contribution in the class seriously" (Dysthe, 1997 p. 63). This perception may help to explain the situation from Fig 1.6 where Laurillard's comment sparked a dialogue among learners in the MOOC.

Communication between teachers and students is only one side of the dialogical learning process we seek to enhance in a MOOC. Also communication between students is substantial, and the use of authentic questions and high valuing must therefore be promoted and fostered amongst the students. Thus the expected obligations of the students are also greatly increased and it is important that students can support and guide each other through dialogue, authentic questions and high valuing as well and jointly build and share knowledge in the ocmmunity.

If we look at BLE through Laurillard's framework developed in Teaching as a Design Science, then the learning currently taking place in the 
course could best be characterized as 'Learning Through Acquisition' (Laurillard, 2012, pp. 105-121). According to Laurillard this form of learning should be supplemented by other forms of learning before, during and after, so the students' learning are not left to themselves (ibid.). This however doesn't seem to be the case in BLE, even though steps are taken towards this by implementing a comment section. If the comment section had been successful, it might have been able to support 'Learning Through Discussion' (Laurillard, 2012, pp. 141161). Unfortunately, the comment section is not integrated in the learning design. That is, the participants does not need to use the comment section or talk to each other at any point during the course. Therefore, the comment section remains a surface structure not moving BLE beyond the banking concept of education in this MOOC. Overall, the only possibility for dialogue in BLE is through asynchronous written communication in the comment section. The strength of this is that written dialogue requires reflection and provides a basis for more abstract and analytical thinking (Dysthe, 1997). This is probably due to the fact, that in an online context such as a MOOC, it can be difficult to support oral synchronous dialogue between thousands of participants. Importantly, the written language calls for greater demands in form, content and clarity to ensure that the message, which the sender is interested in sending, is received as it was intended (Dysthe, 1997; Imsen, 2006). Thus, the transition from oral utterance to written words leads to greater requirements of clarity and explicitness, which is dependent on the sender's ability to express him or herself in a way that sets the stage for creating meaning in the interaction with the receiver (Dysthe, 1997). As such, it requires more of the sender in terms of creating dialogue through writing than through speech.

The reason for the limited dialogue in MOOC might therefore rather be found in the context, lack of support and planning, that surrounds the communication between learners, participants and lecturers in the comments section and the abilities of the participants to be part of this and not whether there is synchronous or asynchronous, oral or written communications.

According to Laurillard it is however important to offer both synchronous and asynchronous means of discussion (Laurillard, 2012, p. 151). While the asynchronous communication can offer better opportunity for reflection about one's articulation, the synchronous communication can create experiences of commitment, presence and belonging. This is clearly needed in BLE and the lack of synchronous communication, be that chat, audio or video communication, seems to be a design flaw causing disengagement, lack of community and isolated course work.

When looking at synchronous forms of communication, videoconferences creates a better conceptual development than audio and chat, in online discussions (Laurillard, 2012, p.148). Conceptual development is to be able to develop an understanding through conversations of the peers or teachers concept. This is comparable what Freire (1996) talks about when he talks about dialogue requiring a united praxis, which will also require being able to create an understanding of the dialogical partners concept in order to reach a united reflection. According to Laurillard eye contact facilitates 
negotiation between the conversational parties (Laurillard, 2012, p. 148), which can be related to video communication enabling more nonverbal cues than audio and written communications. (Baym, 2015, p. 59). So, adding a synchronous form of dialogue to MOOCs, achieved through videoconference, might help realizing better commitment, community and conceptual development and facilitate a greater degree of Learning Through Discussion.

The optimal group size for this synchronous dialogue is groups of maximum five participant (Laurillard, 2012, p. 148). Therefore employing such communication tools in BLE would demand participants being divided into smaller groups in the MOOC. It seems clear, given the number of participants that if discussion is to be the basis for learning in a MOOC this will have to be through peer discussion. Given the Massive nature of MOOC's it seems unmanageable that the teacher should be able to facilitate and partake in all discussions. Laurillard recommends that in order for peer dialogue to be effective each participant must; take a position, give evidence for their claims, consider and criticize each other's ideas, critically reflect own perspectives in comparison with others perspectives, work towards a shared output in collaboration about a decision and use what they have learned (Laurillard, 2012, p. 143). This harmonizes with Freire's (1996) idea of united praxis, entailing both reflection and action between the parties.

A design which wants dialogue and discussion also

have to facilitate the participants towards engaging in this, it can not be expected that the participant engage just because they have the opportunity (Laurillard, 2012, p. 191) - it must be something supported, promoted and fostered by the learning design. One way to move towards this is by using Learning Through Collaboration. Here, the students will have to take part in building knowledge, a shared one, in the process towards a shared product (Laurillard, 2012, p. 187). An advantage of Learning through Collaboration is Peer Modelling, which entails being able to create a representation of another person's thoughts in order to come to a shared understanding and produce something in together. This brings about shared understanding and gives feedback on what the students need to produce (Laurillard, 2012, p. 190). In this way Learning Through Collaboration can get the student to engage in discussions and dialogue in order to overcome conflicts and challenges because they work with focus on a shared product. (Laurillard, 2012, p. 191)

By moving towards a design where the participant of BLE have to work together towards producing a shared product we can ensure that they engage in working towards a shared understanding through discussion and dialogue. Thereby Learning Through Collaboration will ensure that they also partake in Learning Through Discussion. By working towards a product we ensure both reflection, which will come working towards shared understanding, and action that comes from actually producing something together. Both of these elements will be shared or as Freire (1996) says united. To achieve this, Laurillard (2012) establishes five roles the teacher as learning designer must take in collaborative learning: 
1. Envision the lesson: create an image of the lesson, plan and organize student tasks.

2. Enable collaboration: arrange small groups or pairs so that one can learn from the other.

3. Encourage students: support learners and provide guidance during knowledge acquisition.

4. Ensure learning: monitor learning processes and check learning outcomes.

5. Evaluate achievement: choose suitable means to assess processes and product of learning. (Laurillard, 2012, p. 192).

To achieve 1) the introductory video presentation can be kept, which is already a part of the design in BLE - it already have rather meticulous lesson plans for each week. To achieve 2) will involve organizing the students into small groups; this could be done automatically by the system. The size of the groups should be maximum five, so at the beginning of the course participant should automatically be divided in groups of five by the learning design. To achieve 3 ) in the BLE poses a bit of a problem in that it would not be possible to support and guide all learners in a MOOC setting. Instead steps should be taken to ensure that the guidance about the subject and how the teamwork is organized, is very clear in the video presentations. Further sufficient learning resources should be available for the learners. To finally achieve 4) and 5) the students could be creating a collaborative product. This could for example be 10 lines about the subject at hand, which could then receive feedback to extent the teachers have resources for. Considering the active participants in the comment sections, this would make a total of 181 group assignments on each assignment. However a rotation could be made so groups was evaluated once a week, not on each assignment. In the current design of BLE as well as our suggested redesign for increased dialogue we need to consider that participant may have different cultural predisposition for participating in dialogue and collaborative work.

In a recent study Liu et.al.(2016) shows that there are significant different in how students participate in MOOCs, showing developing countries to have a significantly higher proportions of

'solver' participants than developed countries.(Liu et.al, 2016,

p.5) Meaning they focus more on quizzes. (Liu et.al, 2016, p.4) This reflect different educational traditions, where Asia is more test-centric.(Liu et.al, 2016, p.5)

Liu et.al(2016) further found that participants from countries with high power distance tend to have less forum interaction than than participants from countries with lower power distance. (Liu et.al, 2016, p. 7) Finally they found that that Chinese and Brazilian participants tend to interact with people in their own cultural group (ibid.). This indicates that cultural predispositions need to be taken into consideration when interpreting the design of BLE and the lack of dialogue. 
A redesign for dialogue in UID as MOOCs, may end up having adverse effects on participants from cultures not accustomed to low power distance whom are dependent on teacher instruction. The teacher's presence might therefore be required in some degree for these students and a form of evaluation might need to be present. Language may be a barrier (ibid.), but could be solved by grouping people according to their cultural group, in collaborative teams. Overall language barrier may have to be taken with a grain of salt, seeing as the vast majority $(77,6 \%)$ of MOOC participants have a bachelor's degree or higher (Unesco, 2013, p. 5) indicating at least some proficiency in english.

\section{Redesign For Dialogue}

With the fundamentals of analyzing and creating M00Cs as learning design for dialogue and critical reflection in previous sections in mind, we propose altering the learning design to better support dialogue and discussion towards enabling an actual community of practice. We alter the learning with a focus on united praxis and dialogue and employ Learning Through Discussion and Collaboration as our primary methodologies. The core concept of the learning design therefore shifts to sharing instead of representation. See fig. 2.5.

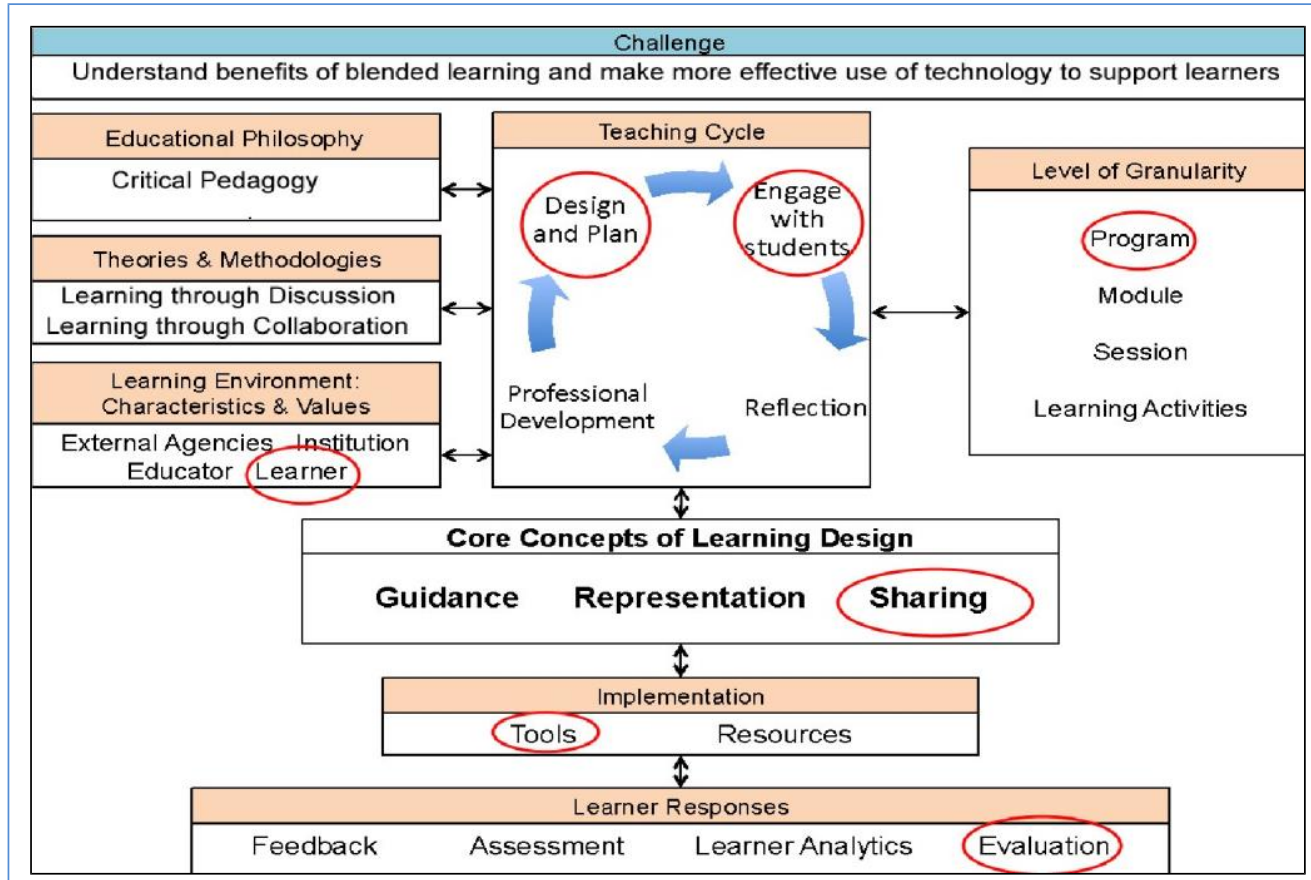

Fig. 2.5 Dalziel et. al., 2012, p. 14

The conceptual map doesn't change much in regards to the original posted under GTM category - Educational Design, however as we have shown, this learning design didn't achieve what the conceptual map of the design promised. Below we have created a pedagogical pattern for the learning re-design, this pattern works on a session level of granularity, when looking at the LD-CM and can be seen as an LD-F. Here we provide a learning design patterns based on 
critical pedagogy that can be used for learning through collaboration and discussion. We employ synchronous and asynchronous means of communication and establish a new media ecology (Scolari, 2012) in the MOOC, which incorporates sharing of resources (e.g. Google Drive), collaborative writing documents (e.g. Google Docs) and synchronous dialogue (e.g. Google Hangout). resources and documents are incorporated as means for collaboration and synchronous dialogue is incorporated as means for creating dialogue while collaborating.

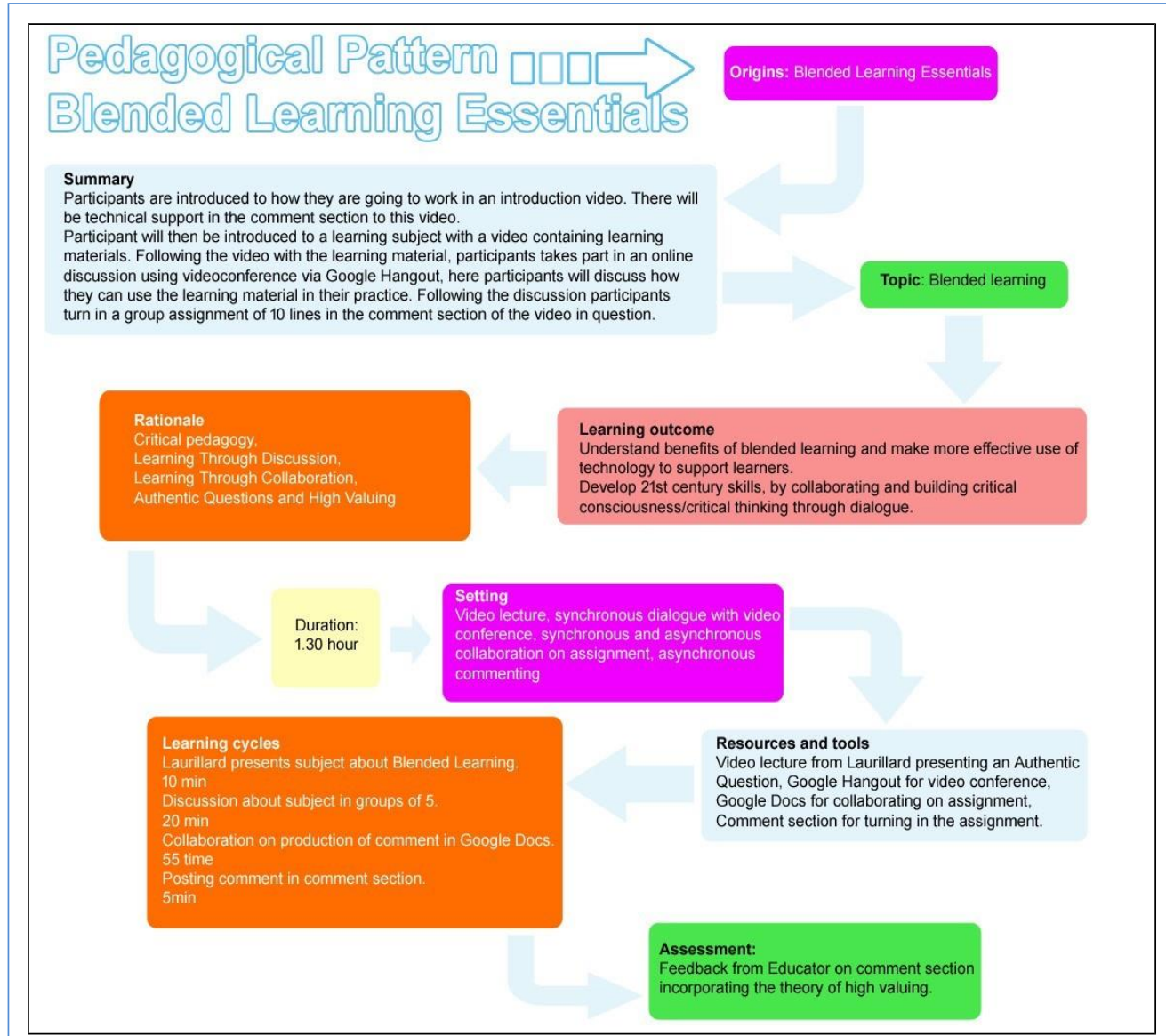

Fig. 2.6

\section{Conclusion}

The current learning design of BLE has a heavy emphasis on video-transmission and multiple-choice tests. The design has comment sections for communicating, leaving the design for communication asynchronous and written as well as totally up to the participants. We have found that only a very little part of the entire amount of participants are active in the comment sections, 907 participants out of 6000 are active in these comment sections. Thus, we see a distinct lack of dialogue even within the group of participants who are active in the comment sections where only 18,34\% of comments are replies and only have an average of 1,8 replies per comment with reply. When looking at the amount of comments for each individual in the MOOC we get a 
curve that resembles a power law curve, where a lot of people comment very little and a little group comment a lot. Looking at top 10 commenters we see that they actually have what might resemble a dialogical comment pattern, indicating that we have a small group of participants that are engaging in continuous dialogue over all 53 comment sections. Looking at where the power law curve picks up we can cut it at 16 comments and divide commenters into dialogical and non-dialogical commenters. 16 comments are on the safe side so we don't cut the curve to late and exclude anyone who might achieve dialogue. This leaves us with 158 dialogical commenters and 749 commenters whose comment patterns are insufficient to achieve dialogue.

From here we can divide MOOC participants into 3 different participant types based on dialogical engagement; Watchers which are not commenting constituting 84,9\% (5093) of the entire population, Commenters which are commenting without engaging in dialogue being $12,5 \%$ (749) of the population and Dialoguers which constitutes 2,6\% (158) of the population.

The learning design of BLE can be said to have strong resemblance with the 'banking concept of education' (Freire, 1996) where the teacher transmit knowledge to the student, the comment section failing to provide a dialogical learning tool for $97,4 \%$ of the participants. This results in a learning design that doesn't support Learning Through Collaboration and Discussion. This causes a lack of critical thinking in the comment sections, which corresponds to Freire's (1996) theory that critical consciousness can only be developed through dialogue. This causes the design to be inefficient in regards to development of 21st century skills.

We suggest that the learning design should be changed and that the focus of this re-design should be Learning Through Discussion and Learning Through Collaboration, in order to move away from the banking concept of education and towards a dialogical learning design which enables the participants to create an united praxis. This will allow participants to develop 21st century skills, the dialogical approach will support critical thinking and learning through collaboration will ensure that collaborative skills are trained.

We have a created a pedagogical pattern which serves as a suggestion for how we can implement these things into the learning design, and which further could be implemented in other MOOC and e-learning designs. This pedagogical pattern remains to be tested and evaluated, leaving it a theoretical suggestion based on the mixed-method research of BLE. The pedagogical pattern requires a new media ecology being implemented to support it. This media ecology is based on e.g. free Google Applications, which makes it possible to actually implementing it in e-learning designs without having a MOOC platform. 


\section{References}

Anderson, T. \& Shattuck, J. (2012). Design-based research: a decade of progress in education research?. Eductional Researcher, Vol 41(1), pp. 16-25.

Attwell, G. (2007). Personal Learning Environments - the future of eLearning? eLearning Papers, Vol 2, № 1, January 2007, ISSN 1887-1542 http://www.informelleslernen.de/fileadmin/dateien/Informelles Lernen/Buecher Dok umente/Attwell 2007-ple.pdf

Bang, J., Dalsgaard, C., O’Donovan, M.M. (2015). Conference Proceedings The Online, Open and Flexible Higher Education Conference, Hosted by Fern Universität in Hagen, 2930 October 2015 (pp. 3956) lokaliseret d. 14.06.2016 på; http://conference.eadtu.eu/images/2015/home/Conference 2015 proce edings def.pdf

Bang, J.(2006) eLearning reconsidered: Have eLearning and virtual universities met the expectations. http://www.openeducationeuropa.eu/es/node/2604

Baym, N.(2015). Personal Connections in the Digital Age. Second Edition. Polity Press. USA.

Brinkmann, S., Tanggaard, L.(2015) Kvalitativ metode: En grundbog. 2. Udgave. Hans Reitzels Forlag. Latvia.

Bryant and Charmaz(2007) The sage handbook of Grounded Theory. Sage Publications Ltd. London, England.

Dalziel, J., Grainne, C., Wills, S., Walker, S., Bennett, S., Dobozy, E., Cameron, L., Badilescu-Buga, E. \& Bower, M. (2013). The Larnaca Declaration on Learning Design. Available at www.larnacadeclaration.org.

Daniel, J., (2012). Making Sense of M00Cs: Musings in a Maze of Myth, Paradox and Possibility. Journal of Interactive Media in Education. Vol 2012(3), p. Art. 18. DOI:http://doi.org/10.5334/2012-18

Dysthe, 0. (1997): Det flerstemmige klasserum - skrivning og samtale for at lære, Klim

Emerson, R., Fretz, R.I. \& Shaw, L.L.(2011). Writing Ethnographic Fieldnotes. The University of Chicago Press. Chicago, United States of America.

Freire, P., (1993): Pedagogy of the oppressed. The Continuum International Publishing Group,London, England

Gynther, K. (2005): Blended learning: it og læring i et teoretisk og praktisk perspektiv. Unge pædagoger. 
Haber, J.(2014) MOOCS. MIT Press.

Hoem, J. (2006). Openness in communication. First Monday Vol. 11 No. 7. Chicago. http://firstmonday.org/htbin/cgiwrap/bin/ojs/index.php/fm/arti cle/view/1367/1286

Jordan, K.(2015) http://www.katyjordan.com/MOOCproject.html

Kanuka, H. \& Anderson, T.: "Ethical Issues in Qualitative ELearning Research", International Journal of Qualitative Methods 6 (2) June 2007

Kozinets, R.(2015) Netnography: Redefined. Sage: London.

Laurillard, D.(2012) Teaching as a Design Science - Building Pedagogical Patterns for Learning and Technology. Routledge.

Laurrilard, D. (2008). The teacher as action researcher: using technology to capture pedagogic form. Studies in Higher Education Vol. 33 (2), pp. 139154.

McKee, Heidi A. and Porter, James E.: "Playing Good Game: Ethical Issues in Researching MMOGs and Virtual Worlds", International Journal of Internet Research Ethics, Vol. 2(1) February 2009

Qvortrup, A. and Wiberg, M., (2013). Læringsteori \& Didaktik. Hans Reitzels Forlag.

Sharples, M., Taylor, J. \& Vavoula, G. (2006). A Theory of Learning for the Mobile Age. In: R. Andrews and C. Haythornthwaite, The Sage Handbook of E-learning Research. Sage Publications. Pp.221-247.

Scolari, C. A. (2012). Media Ecology: Exploring the Metaphor to Expand the Theory. Communication Theory, Vol.22(2), 204225.

Sumner, J.(2000) Serving the System: A critical history of distance education. Open Learning: The Journal of Open, Distance and elearning. Vol. 15, Iss. 3. Pp 267-285.

Unesco (2013) Introduction to Moocs: Avalanche, Illusion or Augmentation? Available at: http://unesdoc.unesco.org/images/0022/002238/223896e.pdf

Zhongxiu Liu, Rebecca Brown, Collin Lynch, Tiffany Barnes, Ryan Baker, Yoav Bergner and

Danielle Mcnamara. (2016). MOOC Learner Behaviors by Country and Culture; an Exploratory Analysis. International Conference on Educational Data Mining (EDM2016), Raleigh, NC, forthcoming. Available at: http://zhongxiuliu.com/publications/EDM16_mooc.pdf 